\title{
Arc-Discharge Synthesis of Iron Encapsulated in Carbon Nanoparticles for Biomedical Applications
}

\author{
S. Chaitoglou, ${ }^{1}$ M. Reza Sanaee, ${ }^{1}$ N. Aguiló-Aguayo, ${ }^{1,2}$ and E. Bertran ${ }^{1}$ \\ ${ }^{1}$ FEMAN Group, IN2UB, Departament de Física Aplicada i Òptica, Universitat de Barcelona, Martí i Franquès 1, \\ E08028 Barcelona, Catalonia, Spain \\ ${ }^{2}$ Institut für Textilchemie und Textilphysik, Universität Innsbruck, Höchsterstraß 73, 6850 Dornbirn, Austria
}

Correspondence should be addressed to S. Chaitoglou; schaitog@gmail.com

Received 24 January 2014; Revised 22 June 2014; Accepted 23 June 2014; Published 13 July 2014

Academic Editor: Ajay Soni

Copyright (C) 2014 S. Chaitoglou et al. This is an open access article distributed under the Creative Commons Attribution License, which permits unrestricted use, distribution, and reproduction in any medium, provided the original work is properly cited.

\begin{abstract}
The objective of the present work is to improve the protection against the oxidation that usually appears in core@shell nanoparticles. Spherical iron nanoparticles coated with a carbon shell were obtained by a modified arc-discharge reactor, which permits controlling the diameter of the iron core and the carbon shell of the particles. Oxidized iron nanoparticles involve a loss of the magnetic characteristics and also changes in the chemical properties. Our nanoparticles show superparamagnetic behavior and high magnetic saturation owing to the high purity $\alpha$-Fe of core and to the high core sealing, provided by the carbon shell. A liquid iron precursor was injected in the plasma spot dragged by an inert gas flow. A fixed arc-discharge current of $40 \mathrm{~A}$ was used to secure a stable discharge, and several samples were produced at different conditions. Transmission electron microscopy indicated an iron core diameter between 5 and $9 \mathrm{~nm}$. Selected area electron diffraction provided evidences of a highly crystalline and dense iron core. The magnetic properties were studied up to $5 \mathrm{~K}$ temperature using a superconducting quantum interference device. The results reveal a superparamagnetic behaviour, a narrow size distribution $(\sigma g=1.22)$, and an average diameter of $6 \mathrm{~nm}$ for nanoparticles having a blocking temperature near $40 \mathrm{~K}$.
\end{abstract}

\section{Introduction}

In the recent years the superparamagnetic particles appear to be important agents for a variety of applications in the fields of drug delivery, magnetic resonance imaging (MRI), and cancer treatments like hyperthermia. This is due to the special magnetic characteristic of these particles. That is the reason of our interest in studying the size limits under which the nanoparticles present a superparamagnetic behaviour [1] .

In order to synthesize nanoparticles in the vapor phase, appropriate conditions should be created. Like in the case described in the capillary theory of nucleation and under supersaturation conditions, a vapor phase mixture in thermal plasma (arc-discharge) can become thermodynamically unstable giving place to a nucleation process [2]. From that and setting particular conditions, it is possible to produce solid phase homogeneous particles in the vapor phase surrounding the hot spot of the arc-discharge.
The method varies depending on the phase of the precursor we are interested to use.

Here, the precursor is injected into thermal plasma which provides the necessary conditions to induce reactions that lead to supersaturation and particle nucleation. Under the condition of thermal plasma, the precursor decomposes in radicals, atoms, and ions forming a high temperature ionized gas. The high concentration of species and high temperatures in the plasma arc induce a diffusion process associated with a fast quenching of gas species. During this process, the gas species react and condense to form particles in a similar way to a vaporized material when cooled down by mixing with a cool gas or expanded through a nozzle [3].

The objective of this work is the control of the synthesis of iron encapsulated in carbon nanoparticles, regarding the size of the Fe core, the diameter of the $\mathrm{C}$ shell, and moreover the quantity of the obtained nanoparticles. Fe is one of the most common materials used for the formation of magnetic 


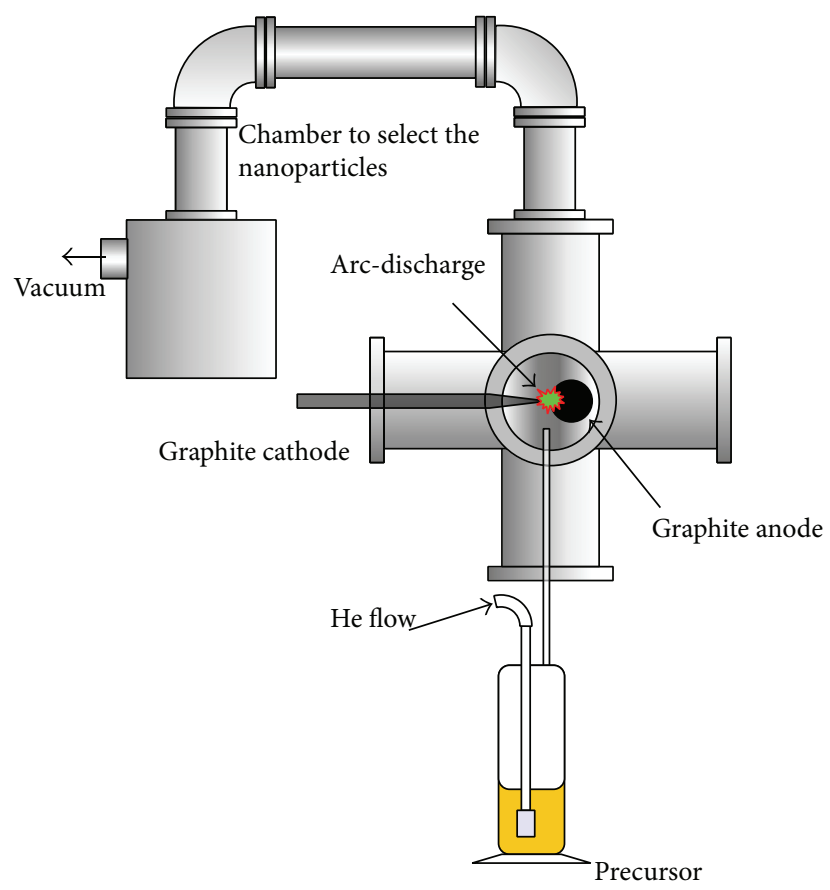

FIGURE 1: General picture of the "home made" reactor we used for the synthesis of the iron encapsulated in carbon nanoparticles.

nanoparticles. It is due to its superparamagnetic behaviour, which is easily controlled by the nanometric size of the magnetic core, and because the Fe is suitable for biomedical applications. The use of a carbon shell is intended to achieve the required biocompatibility and prevents oxidation of the iron core and formation of agglomerations of nanoparticles [4].

The structural and morphological characteristics like shape and size distribution were studied using transmission electron microscopy (TEM) and selected area electron diffraction (SAED). The absence of oxygen was preliminarily evidenced by the energy-dispersive X-ray analysis (STEMEDX). The magnetic characteristics were determined using a superconducting quantum interference device (SQUID).

\section{Materials and Methods}

In order to facilitate the study of magnetic behavior and other characteristics of core@shell nanoparticles, we modified an arc-discharge reactor in order to operate for longer time and produce bigger amounts of them (Figure 1).

To facilitate the complete collection of the produced nanoparticles we dragged them out of the arc-discharge chamber, by a laminar flow of an inert gas $(\mathrm{He})$ to a flask cooled by liquid nitrogen. The flow of the dragging gas that we used was $3 \mathrm{~L} / \mathrm{min}$ of volumetric flow of $\mathrm{He}$ (at $1 \mathrm{~atm}$ ), providing a moderated velocity of $65 \mathrm{~cm} / \mathrm{s}$ in the nozzle outlet. The precursor was in the gas phase. Helium is used to drag microdroplets of ferrocene. The carbon electrodes can be rotated and moved in order to avoid problems that the consumption of carbon could cause. One of the electrodes
TABLE 1: Flow rate and resulting velocity and residence time for a precursor vapor with $1 \%$ of ferrocene concentration.

\begin{tabular}{lcc}
\hline $\begin{array}{l}\text { He flow rate, } \\
\Phi(\mathrm{mL} / \mathrm{min})\end{array}$ & $\begin{array}{c}\text { Precursor vapor } \\
\text { velocity, } \\
U(\mathrm{~cm} / \mathrm{s})\end{array}$ & $\begin{array}{c}\text { Residence time, } \\
\tau(\mathrm{ms})\end{array}$ \\
\hline $30 \pm 2$ & $7.07 \pm 0.50$ & $71 \pm 1.5$ \\
$60 \pm 2$ & $14.13 \pm 0.50$ & $35 \pm 1.5$ \\
$120 \pm 2$ & $28.28 \pm 0.50$ & $18 \pm 1.5$ \\
\hline
\end{tabular}

has a sharp conical tip shape (cathode) and the other has a cylindrical shape with an approximate diameter of $4 \mathrm{~cm}$ and can rotate and move backward and forward (anode). The plasma is being generated by a power supply to produce an arc DC current of $40 \mathrm{~A}$.

The pressure was kept stable at near-atmospheric conditions $\left(5-8 \times 10^{4} \mathrm{~Pa}\right)$. The run period of one experiment was $30 \mathrm{~min}$. Although, to obtain more quantity of product, in principle we can extend the time, it requires having stable conditions during the production process. We used pure $\mathrm{He}$ to drag the precursor compound because plasma becomes more stable [5].

We investigated the effects of two technological parameters, the concentration of the Fe precursor into the solvent isooctane and the total gas flow $(\mathrm{He})$.

Both the isooctane and the Fe precursor (ferrocene) were of a purity of $99.9 \%$.

Residence time is the period that the nucleus of the precursor is spending inside the plasma zone. The time that gas atoms and precursor radicals stay inside the plasma zone depends on the gas flow rate. This has an effect on the size of the particles as the longer they stay inside the plasma zone, the larger they grow [6].

The velocity $u$ and the He flow rate, $\Phi$, are related through the equation

$$
u=\frac{4 \Phi}{\pi d^{2}},
$$

where $d$ is the internal diameter of the cannula through which the gas is targeted in the plasma zone $(\sim 3 \mathrm{~mm})$.

By measuring the size of the plasma zone $h(\sim 5 \mathrm{~mm})$ we can estimate the residence time:

$$
\tau=\frac{h}{u}
$$

Table 1 shows the different residence times for several values of He flow rate.

Different concentrations of Fe precursor into the isooctane, from $1 \%$ to $4 \% \mathrm{w} / \mathrm{w}$, were used to determine the effect on the size of the particles and on the total amount of the obtained product.

\section{Results and Discussion}

Images of nanoparticles were observed by TEM (JEOL 2100) in high resolution mode, using $200 \mathrm{kV}$ and a probe size of $0.5 \mathrm{~nm}$ [7]. Prior to TEM observations, the formed nanoparticles were diluted in methanol and then magnetically filtrated. 
TABLE 2: The iron core diameter average and its standard deviation of all our samples in relation to the two set parameters, He flow rate and ferrocene/isooctane concentration. Samples with $1.1<\sigma_{g}<1.4$ are quite monodisperse. Samples having $\sigma_{g}$ above 1.4 (He flow of 60 sccm and low ferrocene concentration) are bimodal.

\begin{tabular}{|c|c|c|c|}
\hline $\begin{array}{l}\text { He flow rate } \\
(\mathrm{sccm})\end{array}$ & $\begin{array}{c}\text { [Ferrocene/isooctane }] \\
1 \% \mathrm{w} / \mathrm{w}\end{array}$ & $\begin{array}{c}(\mathrm{nm}) / \text { geometric standar } \\
\text { [Ferrocene/isooctane] } \\
2 \% \mathrm{w} / \mathrm{w}\end{array}$ & $\begin{array}{c}\text { [Ferrocene/isooctane] } \\
4 \% \mathrm{w} / \mathrm{w}\end{array}$ \\
\hline 30 & $\begin{array}{c}8.18 / 1.22 \\
\text { (Figure } 2(\mathrm{a}))\end{array}$ & $\begin{array}{c}5.43 / 1.34 \\
\text { (Figure 2(b)) }\end{array}$ & $\begin{array}{c}5.34 / 1.33 \\
\text { (Figure 2(c)) }\end{array}$ \\
\hline 60 & $6.23 / 1.47$ & $6.12 / 1.46$ & $\begin{array}{l}5.22 / 1.22 \\
\text { (Figure 3) }\end{array}$ \\
\hline 120 & $5.22 / 1.25$ & - & - \\
\hline
\end{tabular}

The size distribution of the nanoparticles follows the lognormal function described by Granqvist and Buhrman [8]:

$$
f(D)=\frac{1}{\sqrt{2 D} \ln \sigma_{g}} \exp \left(-\frac{\ln ^{2}(D / \bar{D})}{2 \ln ^{2} \sigma_{g}}\right) .
$$

Here, $D$ is the particle diameter, $\bar{D}$ is the geometric mean, which in a lognormal distribution is equal to its median, and $\sigma_{g}$ is the geometric standard deviation (dimensionless) which describes how spread out are the set of core diameters from the geometric mean. Figure 2 shows several pictures as example of the obtained particles for different flows and concentrations. Figure 2(a) shows a TEM image of nanoparticles obtained with a precursor flow of $30 \mathrm{~mL} / \mathrm{min}$, in a concentration of $1 \% \mathrm{w} / \mathrm{w}$. Actually, this is the only sample that presents an important difference in the size distribution from all the others (average diameter of $8.18 \mathrm{~nm}$ ). When the precursor concentration was doubled to $2 \% \mathrm{w} / \mathrm{w}$, the iron core average size decreased to $5.43 \mathrm{~nm}$ (Figure 2(b)). Figure 2(a) shows how the carbon forms a shell around the Fe core. The shell of carbon in this sample is measured to be between 4 and $6 \mathrm{~nm}$ thick. After doubling the precursor concentration to $4 \% \mathrm{w} / \mathrm{w}$, the size of these particles remains quite constant to $5.34 \mathrm{~nm}$, but the total amount and density of nanoparticles increase (Figure 2(c)). From Table 2, when the precursor concentration is kept to $1 \% \mathrm{w} / \mathrm{w}$, an increase of the He flow produces a decrease in the iron core size. Residence time can explain this behavior only for conditions of low precursor concentrations. At higher precursor concentrations, residence time seems to have no influence on the iron core size. This behavior could be associated with the increase of the nucleation inducing an increase in the particle concentration, as evidenced by comparing Figures 2(b) and 2(c). This phenomenon could be related to the reduction of the supersaturation conditions, establishing a competitive mechanism limiting the resulting iron core size.

Another detail in the micrographs of Figure 2 is the absence of coalescence. This indicates a low concentration of nucleus during the growth process for the conditions listed in Table 2.

By treating all the size distribution results with ORIGIN tools, $\bar{D}$ and $\sigma_{g}$ were determined. To measure the diameter of the nanoparticles we used ImageJ, a free software tool for image processing and analysis. Figure 3 shows the histogram of the size distribution for the nanoparticles which have been synthesized under a precursor flow of $60 \mathrm{~mL} / \mathrm{min}$ and a ferrocene concentration of $4 \% \mathrm{w} / \mathrm{w}$. The resulting geometric size average is $5.22 \mathrm{~nm}$ and the geometric standard deviation 1.22 .

All the studied samples (Table 2) present a size distribution of the iron core between $5.22 \mathrm{~nm}$ and $8.18 \mathrm{~nm}$. This could be due to the stabilization of the growth of the carbon shell after reaching the critical radius of a carbon sphere. Under this hypothesis, the formation of a stable carbon shell would limit the $\mathrm{Fe}$ core growth. According to the studies reported by Kuznetsov et al. [9], the nucleation of carbon on the surface of the metal catalyst is something common for all kinds of carbon deposits. The difference in morphology of the carbon deposits depends on the reaction conditions and on the nature of the metal catalyst. A thermodynamic analysis of the effect of different reaction parameters on the critical radius of the carbon nucleus was performed and showed that an increase in the temperature can be responsible for the formation of smaller nuclei.

Another interesting fact supporting the formation of a carbon shell on the iron nanoparticles is that the use of metals, which are characterized by a higher metal-carbon energy bond, yields nanotubes of smaller radius [9]. In these studies, the critical radius of the carbon is related to the change in Gibbs free energy during the nucleation [9]. The only sample that seems not to follow this assumption is the one grown under conditions of $1 \% \mathrm{w} / \mathrm{w}$ of $\mathrm{Fe}$ concentration and precursor flow of $30 \mathrm{~mL} / \mathrm{min}$. This result could be related to the higher residence time associated with a low flow rate, which leads to an increase in the core size and a delay in reaching the conditions of carbon supersaturation located outside the hot plasma region.

To discuss the size distribution of our samples we can rely on the geometric standard deviation, $\sigma_{g}$. The results of size and dispersion of iron cores along with their experimental parameters are listed in Table 2. A geometric standard deviation lower than 1.1 indicates a monodisperse size distribution, whereas for values above 1.4 indicates a wide distribution of size. Between these two values the size distribution is considered quite monodispersed. When the dispersion is larger than 1.4, the size distribution is considered to be 

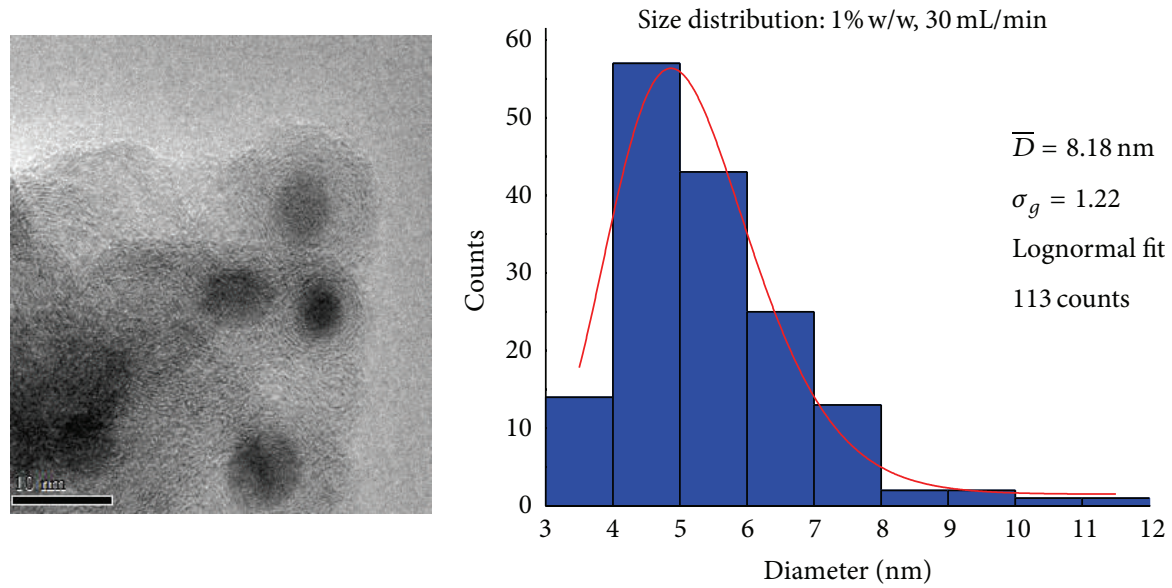

(a)
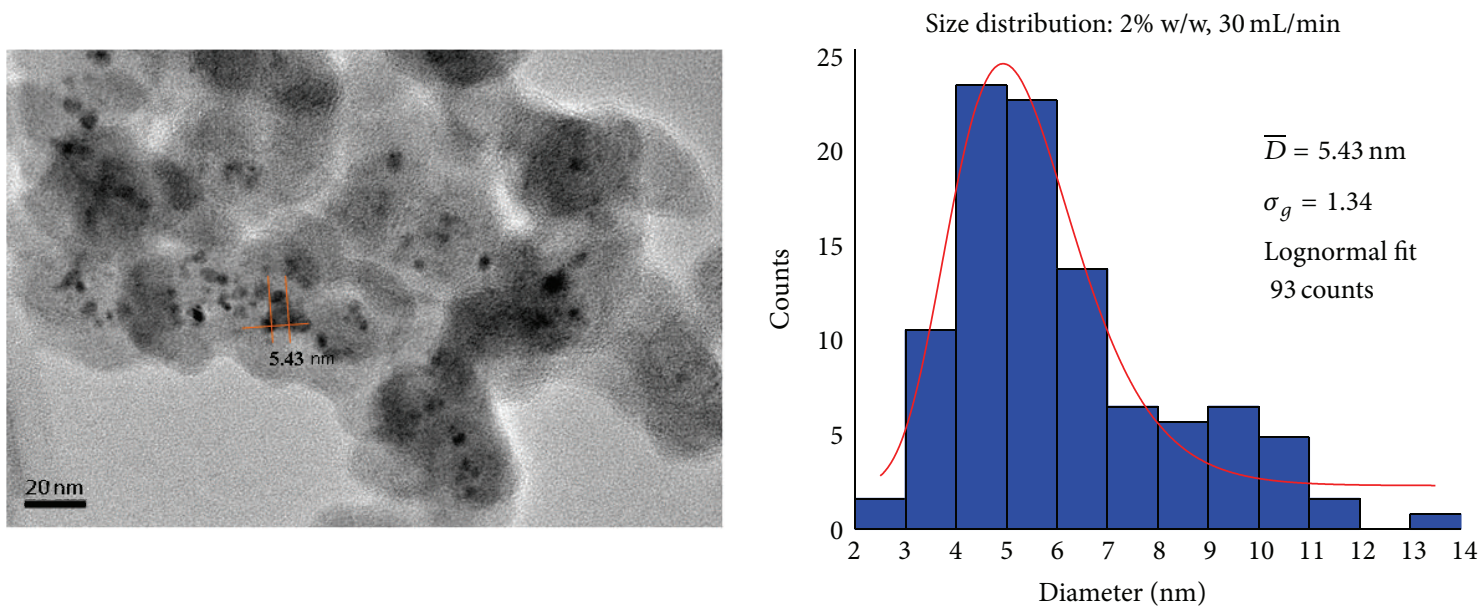

(b)
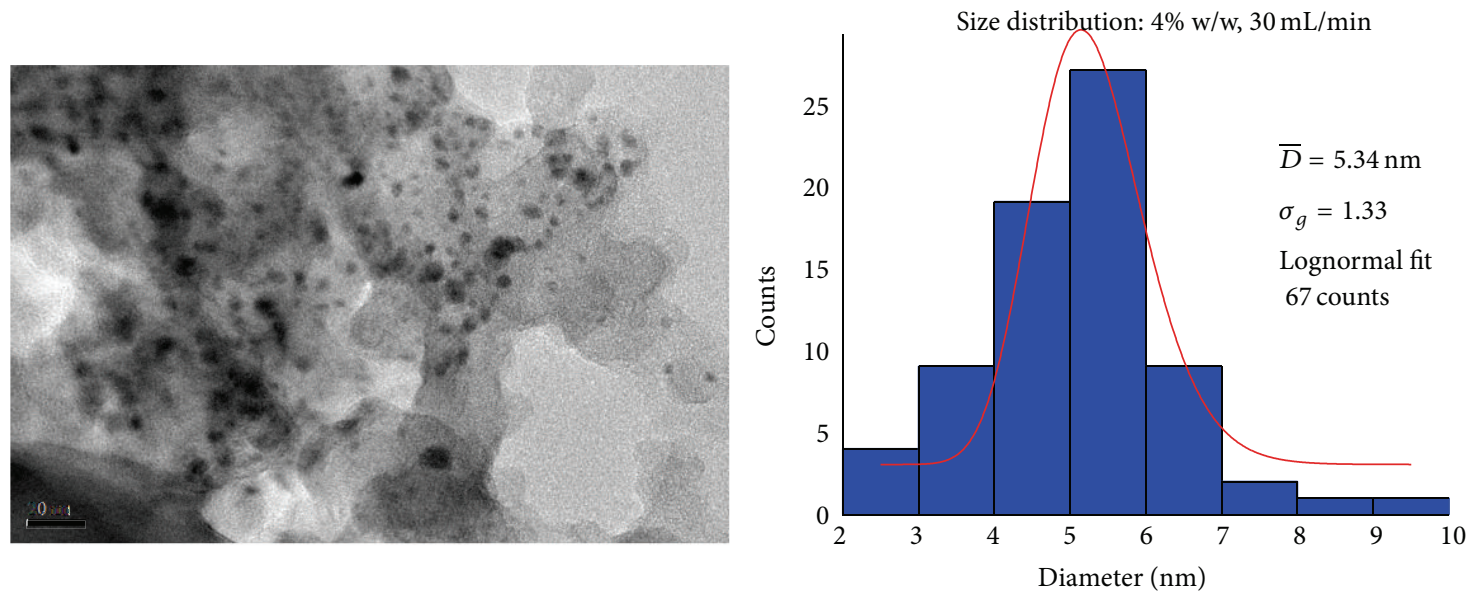

(c)

Figure 2: TEM images of iron encapsulated in carbon nanoparticles produced by arc-discharge (40 \pm 5 A of current) using different flows and concentrations accompanied by their size distribution histograms. (a) $30 \mathrm{~mL} / \mathrm{min}$ with a concentration of $1 \% \mathrm{w} / \mathrm{w}$, (b) $30 \mathrm{~mL} / \mathrm{min}$ with a precursor concentration of $2 \% \mathrm{w} / \mathrm{w}$, and (c) $30 \mathrm{~mL} / \mathrm{min}$ with a concentration of $4 \% \mathrm{w} / \mathrm{w}$. 


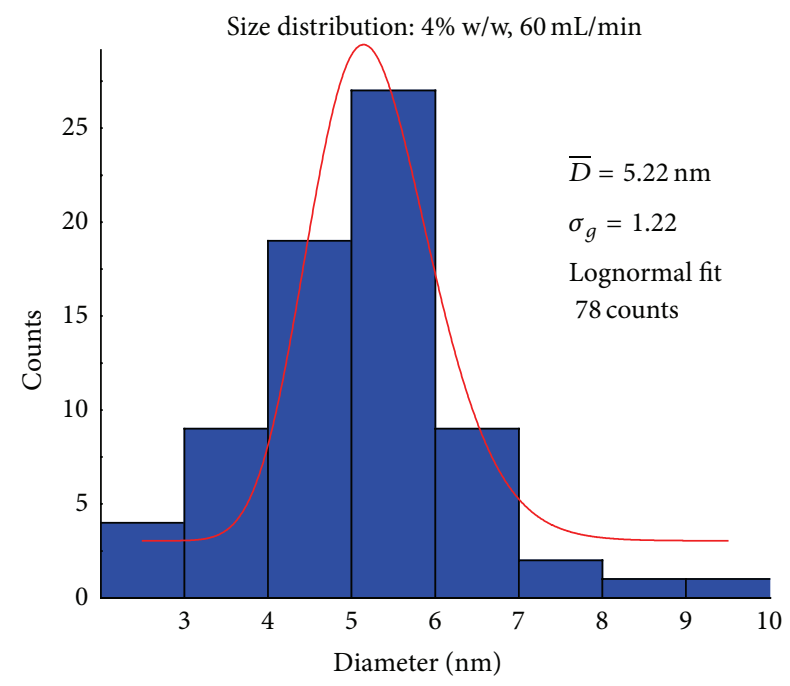

Figure 3: Histogram of the size distribution for iron nanoparticles grown under precursor concentration of $4 \% \mathrm{w} / \mathrm{w}$ and He flow of $60 \mathrm{~mL} / \mathrm{min}$. The iron core is $5.22 \mathrm{~nm}$ and the geometric standard deviation $\sigma 1.22$.

bimodal [10]. Table 2 lists the level of dispersion of the different samples.

The absence of oxygen in the spectrum was preliminarily evidenced by the energy-dispersive X-ray analysis (STEMEDX). Oxygen peak is not present in the spectrum in the expected energy $(\mathrm{O}-\mathrm{K} \alpha$ at $525 \mathrm{eV})$, which indicates a low level of oxygen. In addition, an HRTEM picture of a iron encapsulated in carbon nanoparticle was taken (Figure 4). To obtain the crystal structure of the iron core and the carbon shell, we calculated its fast Fourier transform (inset of Figure 4). The only phases evidenced from this figure were the $\alpha$-Fe $(d$-spacing $=0,202 \mathrm{~nm})$ and the iron carbide $(d$ spacing $=0,221 \mathrm{~nm})$. No diffraction points of iron oxides were detected [11] in any of our samples. The phases of iron carbide probably are located in the interface between the iron core and the carbon shell. As we comment below from the magnetic measurements, the content of the iron carbide phase is minor if compared with the $\alpha$-Fe.

In addition carbon shell appears surrounding completely the iron cores forming crystalline domains with a structure similar to the fullerene one.

This result suggests that iron core is completely sealed into the cover shell, which is of great importance and interest in biomedical applications [12].

SQUID measurements were used to investigate the magnetic characteristics of our samples. Two hysteresis loops (Figure 5) of different samples were studied to compare their characteristics. Samples of Figures 5(a) and 5(b) were produced by means of a precursor gas flow of $30 \mathrm{~mL} / \mathrm{min}$ and with a precursor concentration of $1 \% \mathrm{w} / \mathrm{w}$ and $2 \% \mathrm{w} / \mathrm{w}$, respectively.

From the hysteresis loop measured by SQUID at $5 \mathrm{~K}$ we have obtained the coercive field $H_{C}$. For the sample of the $2 \% \mathrm{w} / \mathrm{w}$ concentration having a diameter $5.43 \mathrm{~nm}$, this is $0.03 \mathrm{~T}$ and, for the sample of $1 \% \mathrm{w} / \mathrm{w}$ with a diameter of $8.18 \mathrm{~nm}$, it is $0.05 \mathrm{~T}$. These results come in agreement with other results which indicates the influence of the size on the magnetization when it comes to superparamagnetic nanoparticles [13].

Subsequently we compare the values of the coercive field with those reported in the bibliography for magnetic nanoparticles encapsulated in carbon nanotubes [14]. We have calculated the critical radius of the iron consisting of uniaxial nanoparticles. To achieve this, we use the NeelArrhenius equation [15] for blocking temperatures $T_{B}=40 \mathrm{~K}$ and $k_{B}=1.380 \cdot 10^{-23} \mathrm{~J} / \mathrm{K}$ assumed. Then, from the equation,

$$
T_{B}=\frac{K \cdot V}{k_{B} \cdot \log \left(t_{m} / t_{0}\right)}
$$

where the factor $\log \left(t_{m} / t_{o}\right)=25, t_{m}$ is the measuring time of the SQUID (100 s), and $t_{0}$ is the characteristic relaxation time. The value $K$ is the anisotropy energy density $(K=$ $4.8 \times 10^{4} \mathrm{~J} / \mathrm{m}^{3}$ for Fe bulk) and the volume is as follows:

$$
V=\frac{4 \pi}{3} \frac{d^{3}}{8}
$$

where $d$ is the diameter of the core. From the above relations the critical radius is calculated to be $4.09 \mathrm{~nm}$. The theoretical graph shows the connection of the radius of the nanoparticles to $H_{C}$ and the comparison with the values of the samples shows an agreement. To obtain the curve, the following equation is used [16]:

$$
H_{C}=H_{\mathrm{CO}}\left[1-\left(\frac{D_{P}}{D}\right)^{3 / 2}\right] .
$$

In this equation, $H_{\mathrm{CO}}$ is the field that should be applied in order to demagnetize the bulk material, $D_{P}$ is the critical radius below which our particles become superparamagnetic, and $D$ is the real radius of the sample. For particles of $5.43 \mathrm{~nm}$ we expect a coercive field $H_{C}=0.035 \mathrm{~T}$. The coercive field from our sample of this size is measured to be $0.030 \mathrm{~T}$, which is a value very close to the theoretical one. For nanoparticles of a diameter around $8.1 \mathrm{~nm}$ the theoretical value of $H_{C}$ is expected to be $0.053 \mathrm{~T}$. The value of our sample of this diameter is $0.050 \mathrm{~T}$ which is also in agreement with the theoretical one. In the case of very small nanoparticles, one can observe superparamagnetic behavior related to the fact that a demagnetization effect arises from the additional energy of the magnetic fields outside the graphitic carbon encapsulation [17].

SQUID measurements of a sample in concentration of $1 \%$, in a precursor gas flow of $60 \mathrm{~mL} / \mathrm{min}$, and in temperatures of 5 and $300 \mathrm{~K}$ were taken. In Figure 6 the normalized magnetization versus the applied field can be seen. The ratio of remnant to saturation magnetization both at $5 \mathrm{~K}$ and in room temperature is 0.9 , less than 0.25 which is the value for the paramagnetic materials, so the carbon-coated iron nanoparticles are superparamagnetic materials [18].

From the zero field cooled and the field cooled curve it can be seen that the nanoparticles are superparamagnetic in room temperature. The blocking temperature appears near $40 \mathrm{~K}$, where the maximum of the ZFC magnetization is localised. 

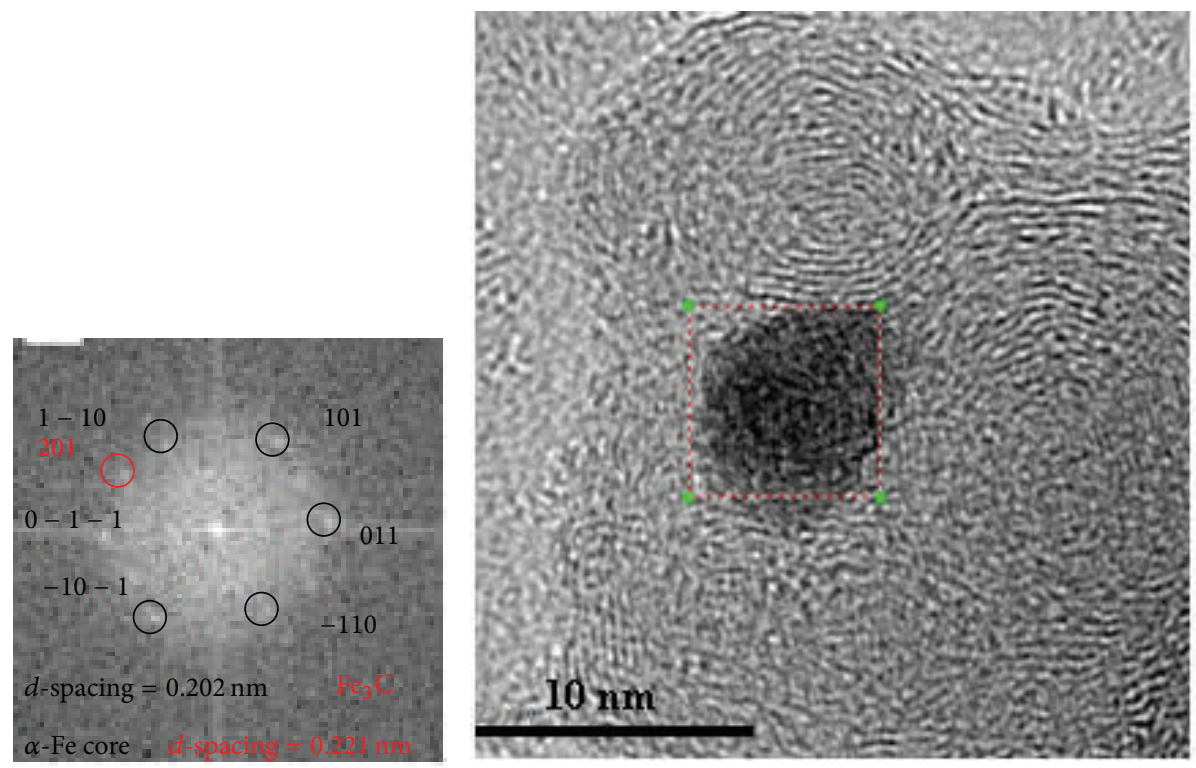

FIGURE 4: TEM image of a nanoparticle. In the small picture we can see the diffraction pattern from which we obtain the crystalline structure of the iron core. Here it corresponds to the $\alpha$-phase.

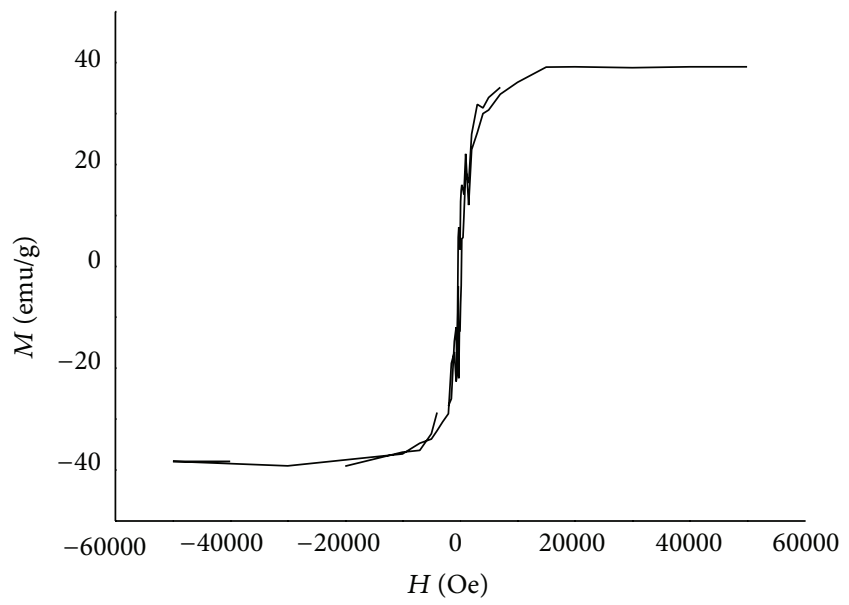

(a)

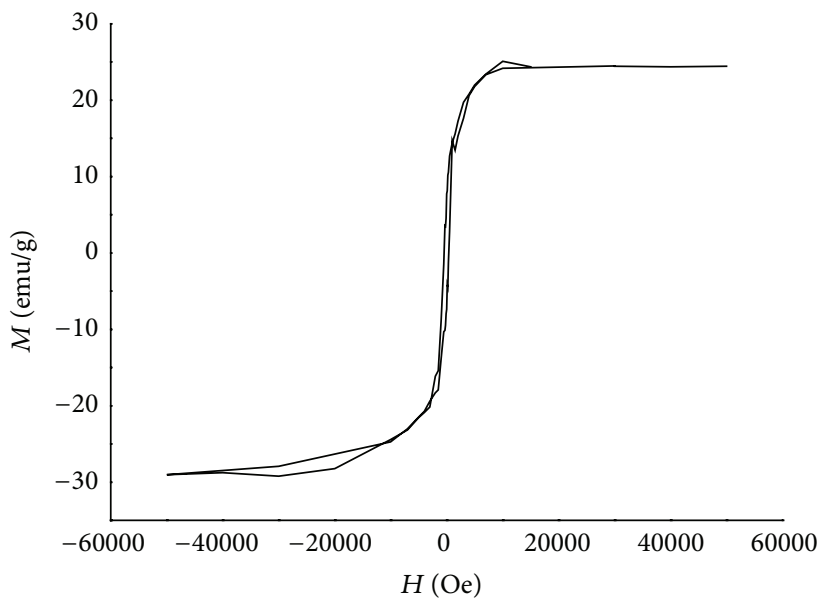

(b)

Figure 5: The hysteresis loops measured at $5 \mathrm{~K}$ for samples with different precursor concentrations: (a) $1 \%$ w/w and (b) $2 \%$ w/w. Both were obtained at a precursor gas flow of $30 \mathrm{~mL} / \mathrm{min}$.

Gittleman's model describes blocking temperature and the critical volume that separates nanoparticles from the blocked state $(\mathrm{V}>\mathrm{VP})$ and superparamagnetic state $(\mathrm{VP}>\mathrm{P})$ [19]. Also, as the peak of the zero field cooled curve is quite narrow, we can assume that the size distribution is narrow as well (Figure 7) [20].

\section{Conclusions}

Our proposed synthesis method provides us with the capability of a very good control in the size of the synthesized nanoparticles. Morphological and structural characterization revealed a quite good monodispersion as well as the $\alpha$-phase crystallinity of the iron core, the iron carbide phase, and the absence of oxygen. These are very important factors when it comes to large scale productions, necessary for biomedical applications. The iron core is completely shielded by carbon. The magnetic characterization revealed the superparamagnetic behavior of the particles in temperatures above $300 \mathrm{~K}$. Further research will be done concerning the improvement of the collection process of the nanoparticles in order to have the highest amounts possible per experimental round.

\section{Conflict of Interests}

The authors declare that there is no conflict of interests regarding the publication of this paper. 


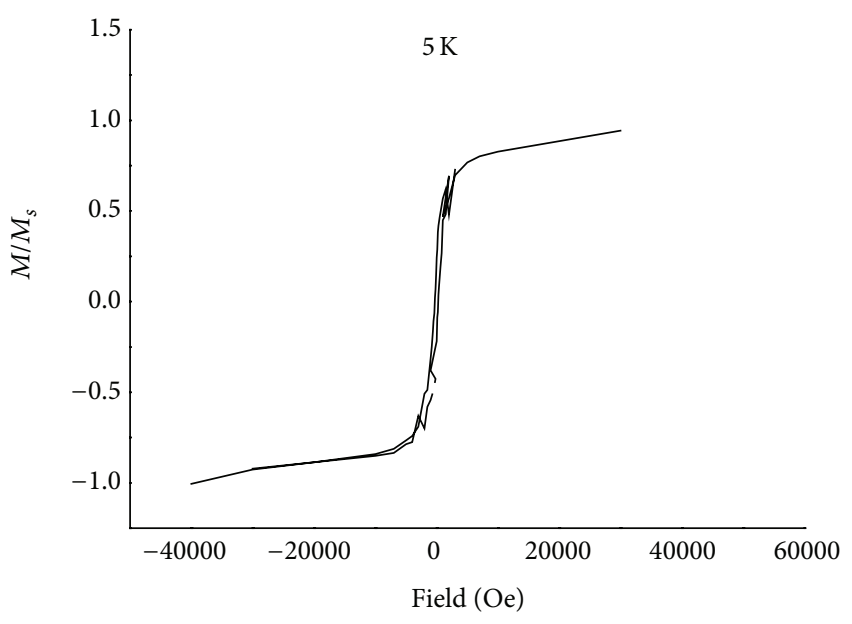

(a)

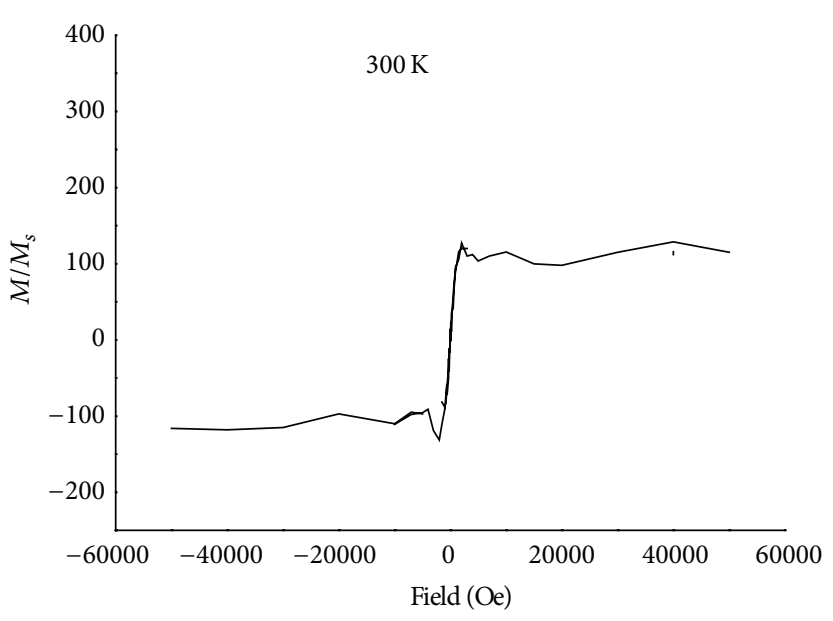

(b)

FIgURE 6: Graphs of the normalized magnetization M/Ms ratio with the field in $5 \mathrm{~K}$ and room temperature.

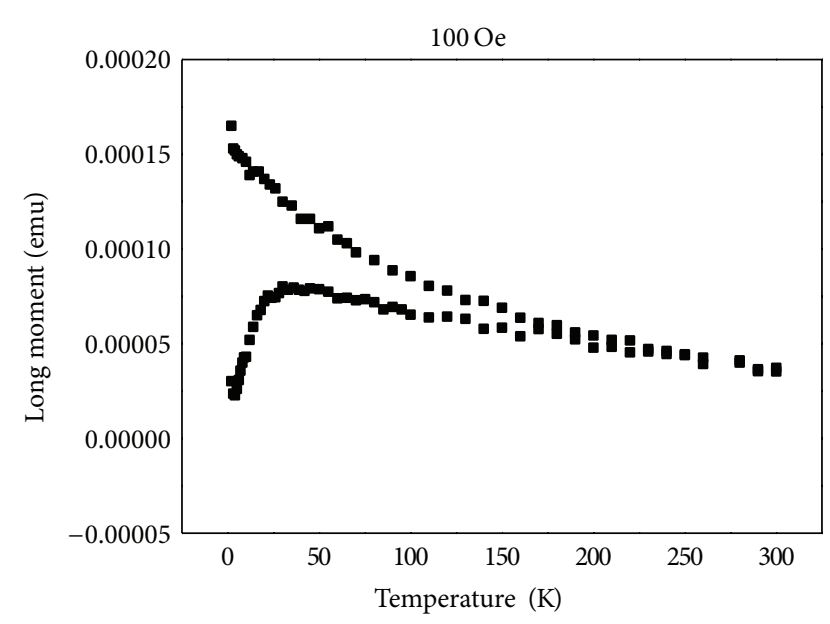

Figure 7: Zero fields cooled and the field cooled magnetization curves for 100 Oe field.

\section{Acknowledgments}

This work was supported by AGAUR of Generalitat de Catalunya, Project 2009SGR00185, and by MICINN of Spanish Government, Projects CTQ2009-14674-CO2-01 and CSD2006-12. The authors would like to thank the State Scholarships Foundation of Greece (IKY) for the financial support. Also, they would like to thank the people of the Centres Científics i Tecnològics de la UB, CCiTUB, and Nuria Clos for the help with the SQUID measurements.

\section{References}

[1] C. Martínez-Boubeta, K. Simeonidis, M. Angelakeris et al., "Critical radius for exchange bias in naturally oxidized $\mathrm{Fe}$ nanoparticles," Physical Review B, vol. 74, no. 5, Article ID 054430, 2006.
[2] B. I. Kharisov, H. V. Rasika Dias, O. V. Kharissova, V. Manuel Jiménez-Pérez, B. Olvera Pérez, and B. Muñoz Flores, "Ironcontaining nanomaterials: synthesis, properties, and environmental applications," RSC Advances, vol. 2, no. 25, pp. 93259358, 2012.

[3] M. T. Swihart, "Vapor-phase synthesis of nanoparticles," Current Opinion in Colloid and Interface Science, vol. 8, no. 1-2, pp. 127-133, 2003.

[4] N. Sounderya and Y. Zhang, "Use of core/shell structured nanoparticles for biomedical applications," Recent Patents on Biomedical Engineering, vol. 1, pp. 34-42, 2008.

[5] Y. Ando and X. Zhao, "Synthesis of carbon nanotubes by arc-discharge method," New Diamond and Frontier Carbon Technology, vol. 16, no. 3, pp. 123-137, 2006.

[6] M. Vardelle, A. Vardelle, P. Fauchais, K. Li, B. Dussoubs, and N. J. Themelis, "Controlling particle injection in plasma spraying," Journal of Thermal Spray Technology, vol. 10, no. 2, pp. 267-284, 2001.

[7] http://www.jeol.com/products/electronoptics/transmissionelectronmicroscopestem/200kv/jem2100f/tabid/124/default.aspx.

[8] C. G. Granqvist and R. A. Buhrman, "Log-normal size distributions of ultrafine metal particles," Solid State Communications, vol. 18, no. 1, pp. 123-126, 1976.

[9] V. L. Kuznetsov, A. N. Usoltseva, A. L. Chuvilin et al., "Thermodynamic analysis of nucleation of carbon deposits on metal particles and its implications for the growth of carbon nanotubes," Physical Review B. Condensed Matter and Materials Physics, vol. 64, no. 23, Article ID 235401, 2001.

[10] H. G. Merkus, Particle Size Measurements: Fundamentals, Practice, Quality, vol. 17 of Overview of Size Characterization Techniques, Springer Particle Technology Series, Springer, New York, NY, USA, 2009.

[11] N. Aguiló-Aguayo, M. J. Inestrosa-Izurieta, J. García-Céspedes, and E. Bertran, "Morphological and magnetic properties of superparamagnetic carbon-coated Fe nanoparticles produced by arc discharge," ASP Journal of Nanoscience and Nanotechnology, vol. 10, no. 4, pp. 2646-2649, 2010. 
[12] K. D. Bakoglidis, K. Simeonidis, D. Sakellari, G. Stefanou, and M. Angelakeris, "Size-dependent mechanisms in AC magnetic hyperthermia response of iron-oxide nanoparticles," IEEE Transactions on Magnetics, vol. 48, no. 4, pp. 1320-1323, 2012.

[13] B. S. Han, C. K. Rhee, M. K. Lee, and Y. R. Uhm, "Synthesis of nano crystalline $\mathrm{Ni}$ and $\mathrm{Fe}$ by levitational gas condensation method," IEEE Transactions on Magnetics, vol. 42, no. 11, pp. 3779-3781, 2006.

[14] D. Gozzi, A. Latini, G. Capannelli et al., "Synthesis and magnetic characterization of Ni nanoparticles and Ni nanoparticles in multiwalled carbon nanotubes," Journal of Alloys and Compounds, vol. 419, no. 1-2, pp. 32-39, 2006.

[15] L. Néel, "Théorie du traînage magnétique des ferromagnétiques en grains fins avec applications aux terres cuites," Annals of Geophysics, vol. 5, pp. 99-136, 1949.

[16] B. D. Cullity and C. D. Graham, Introduction to Magnetic Materials, Wiley, 2009.

[17] Y. R. Uhm, C. K. Rhee, H. M. Lee, and C. S. Kim, "Magnetic properties and dispersion stability of carbon encapsulated Fe nano particles," Journal of the Korean Physical Society, vol. 57, no. 6, pp. 1609-1613, 2010.

[18] C. Jin, Z. Haiyan, L. Liping et al., "Super-par amagnetic carbon coated iron nanoparticles and biological magnetic induction heating properties," Digest Journal of Nanom Aterials and Biostructures, vol. 8, no. 1, pp. 43-51, 2013.

[19] J. I. Gittleman, B. Abeles, and S. Bozowski, "Superparamagnetism and relaxation effects in granular $\mathrm{Ni}-\mathrm{SiO}_{2}$ and $\mathrm{Ni}-\mathrm{Al}_{2} \mathrm{O}_{3}$ films," Physical Review B, vol. 9, no. 9, pp. 3891-3897, 1974.

[20] M. F. Hansen and S. Mørup, "Estimation of blocking temperatures from ZFC/FC curves," Journal of Magnetism and Magnetic Materials, vol. 203, no. 1-3, pp. 214-216, 1999. 

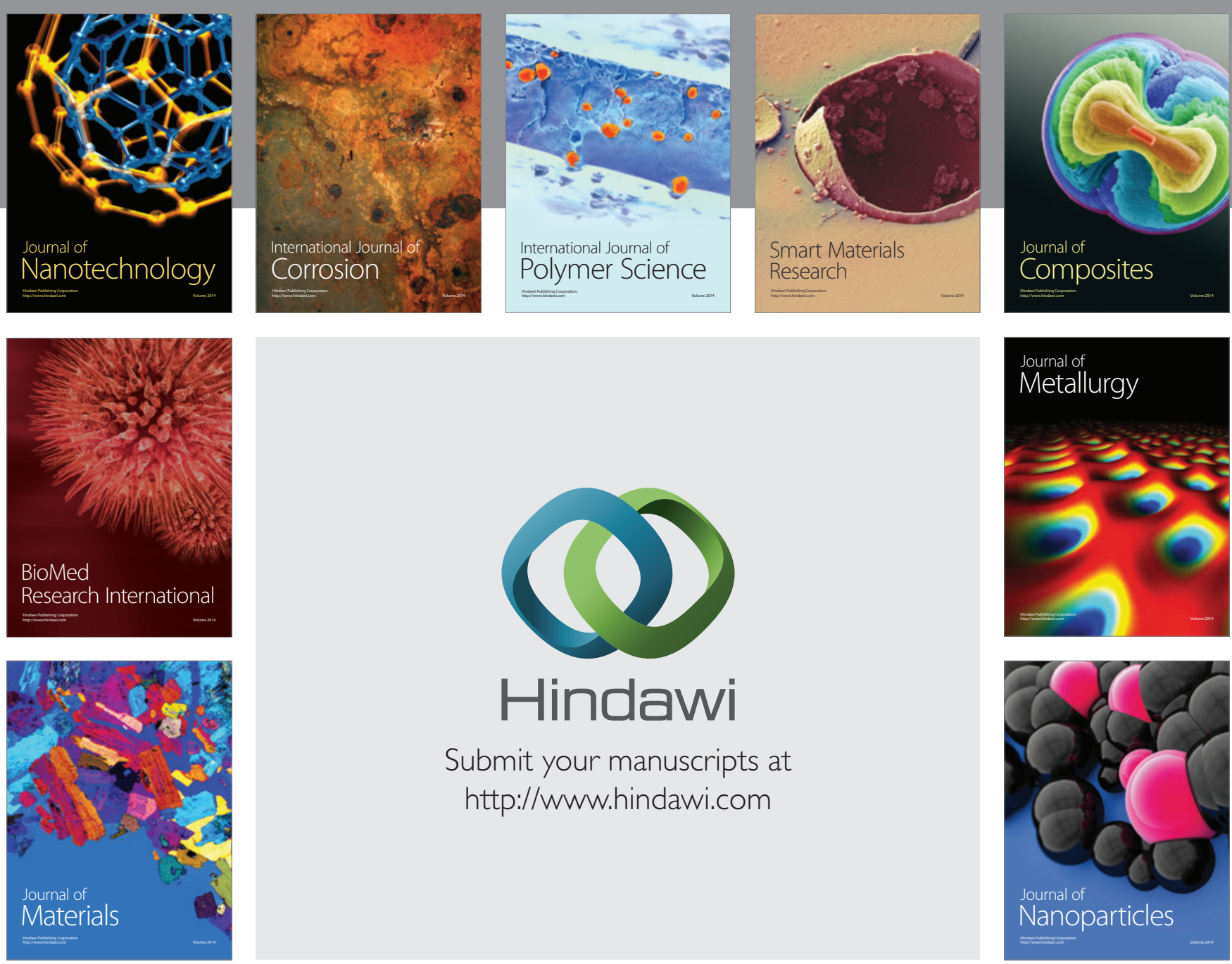

Submit your manuscripts at http://www.hindawi.com
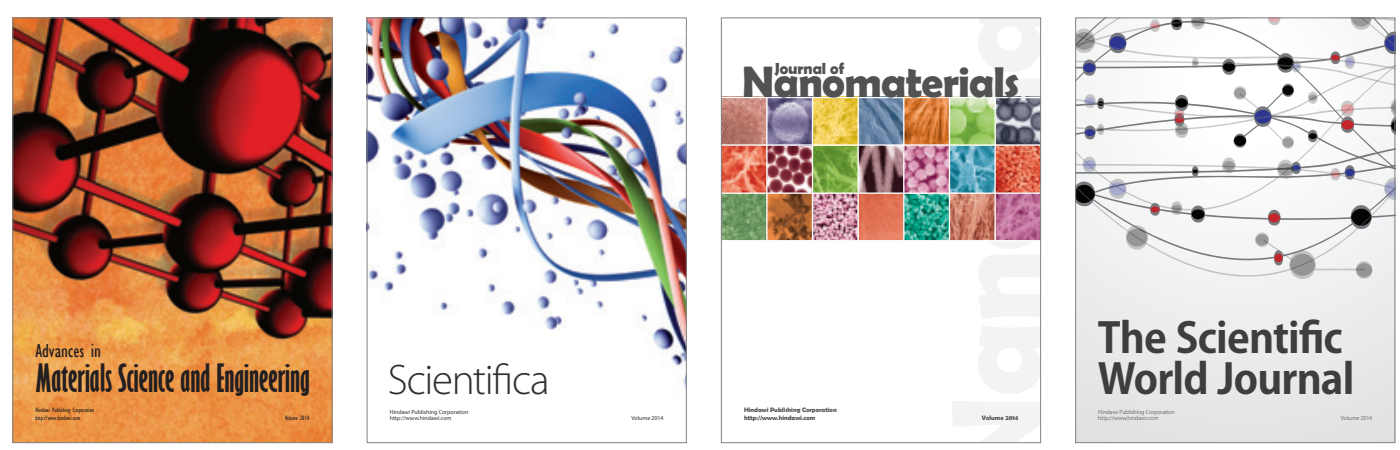

\section{The Scientific World Journal}
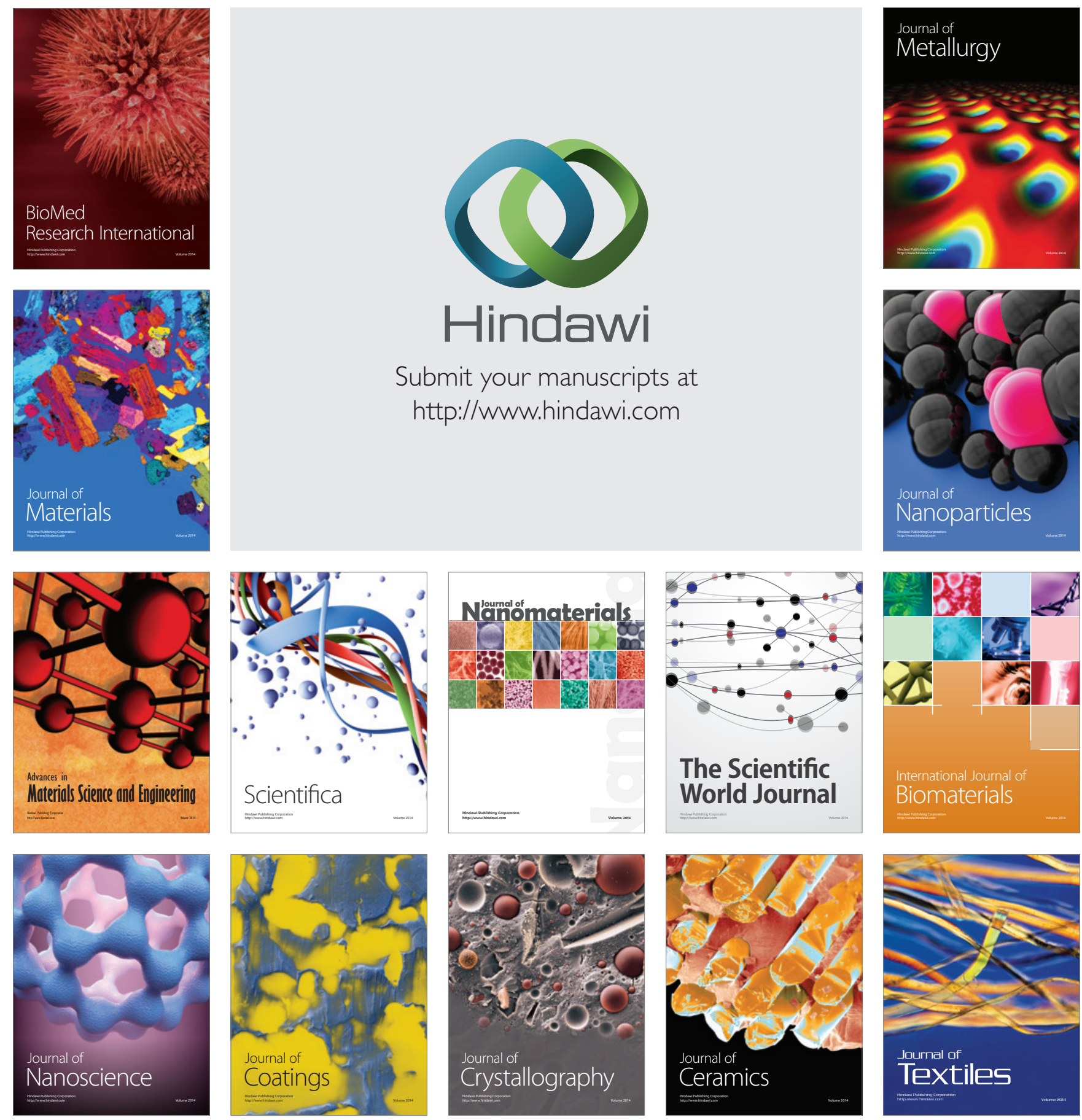